5. Postawa wdzięczności. Na ostatnim miejscu, chciałbym wspomnieć także inną niezwykle wyrazistą cechę osobowości ks. prof. Franciszka - postawa wdzięczności. Prezentuje ją Ksiądz Jubilat w swojej Autobiografii i - co jest charakterystyczne - co rusz wszystkim dziękuje. Jest wdzięczny wszystkim, których spotkał - są wśród nich hierarchowie, uczniowie, dziś profesorowie, ale i zwykli klerycy, z którymi mógł pojechać w Bieszczady. Piękna to cecha - wdzięczność. Wspaniale ujął to Jubilat w zakończeniu swej Autobiografi:

„Wdzięczność jest miarą szlachetności człowieka, niewdzięczność - miarą jego podłości. Wdzięczność jest swego rodzaju sprawiedliwością. Nie ma szlachetniejszej przesady niż przesadna wdzięczność. Nieustannie proszę Boga by mnie uchronił od grzechu Lucyfera - od grzechu niewdzięczności”.

Myślę, że ten cytat doskonale oddaje duchowość ks. Franciszka.

Drogi Jubilacie! Ale to jednak my dzisiaj w sposób szczególny jesteśmy wdzięczni Tobie za pracę, za przykład pracowitego życia, za ciagle ponawiane zaufanie Bogu, którego dajesz przykład. Życzymy, aby nie zabrakło wdzięczności dla Ciebie ze strony Twoich uczniów, studentów i słuchaczy - także radiowych i telewizyjnych - współpracowników i kolegów po fachu. Twoje dalsze prace, zamiary i pragnienia składamy w ręce Boga. I nie zapominaj, że patrologów polskich cechuje klimat rodzinności, co nieustannie jest podkreślane, klimat, który wyraża się nie tylko we wzajemnej życzliwości i wspieraniu się, ale także - jak w rodzinie - gdy jesteśmy ze sobą razem przy okazji różnych spotkań (także i tego spotkania) możemy po prostu odprężyć się i odpocząć. A więc Drogi Jubilacie, Kochany Franusiu, chociaż nie okazujesz zmęczenia, to jednak masz prawo być utrudzony. Spójrz wtedy na grono tak licznych przyjaciół, którzy Cię otaczają nie tylko dzisiaj, ale zawsze, i powtórz za św. Augustynem:

„Chociaż utrudzony jestem urzędem, wypoczywam - dzięki łączności z wami””.

ks. Bogdan Częsz - Poznań, UAM

\title{
6. „LEX” I „RELIGIO” W OKRESIE PÓŹNEGO ANTYKU (XL „Dni Augustiańskie” - Rzym, 10-12 V 2012)
}

W dniach 10-12 V 2012 r., po raz czterdziesty, po rocznej przerwie spowodowanej gruntowną przebudową budynków Instytutu Patrystycznego „Augustinianum”, spotkali się w Rzymie badacze starożytności chrześcijańskiej. Tym razem tematem trzydniowych obrad było zagadnienie „Lex” $\boldsymbol{i}$ „religio” w okresie późnego antyku (,Lex” et ,,religio” in età tardoantica). Temat konferencji został zaczerpnięty z wypowiedzi Cycerona (Pro Cluentio 58, 159), która została zinterpretowana w nieco odmienny sposób od intencji jej autora, w celu zaadoptowania jej do politycznych, społecznych i religijnych warunków związanych ze zmianami w IV wieku. Do słów Arpinaty nawiązywał niewątpliwie Orozjusz, który u początku V wieku pisał: „ubique patria, ubique lex et religio mea est" (Historiae adversum paganos V 2,2). Celem konferencji było zrozumienie wzajemnej relacji oraz zmian znaczeniowych tych ter-

\footnotetext{
${ }^{6}$ Drączkowski, Autobiografia, s. 223.

${ }^{7}$ Augustinus, Sermo 340, 1, PL 38, 1483, tłum. własne.
} 
minów, które miały miejsce zwłaszcza w IV wieku, a także prześledzenie ich odniesień, bądź też odejść od antycznej tradycji rzymskiej w ich stosowaniu.

Czterdzieste spotkanie badaczy antyku chrześcijańskiego rozpoczęło przemówienie dyrektora Instytutu „Augustinianum” prof. Roberta Dodaro OSA, który powitał zgromadzonych gości, przedstawił tematykę spotkania oraz wyjaśnił roczną przerwę w organizacji spotkań, a następnie przekazał prowadzenie obrad J.E. Kardynałowi Prosperowi Grechowi OSA, wybitnemu bibliście i współzałożycielowi, wraz z o. prof. Agostino Trapè OSA, Instytutu Patrystycznego „Augustinianum”, który kilka miesięcy wcześniej został przez papieża Benedykta XVI wyniesiony do godności kardynalskiej. Zanim rozpoczęły się obrady, przełożony generalny Ojców Augustianów, o. Robert F. Prevost OSA, dokonał poświęcenia nowej „Aula Magna” Instytutu, będącej owocem zakończonych prac renowacyjnych w budynku, a następnie chór chłopięcy klasztoru San Lorenzo de El Escorial pod dyrekcją o. Pedro Alberto Sáncheza OSA wykonał 3 utwory ze swojego repertuaru. W ten sposób ubogaceni uczestnicy przystapili do zasadniczej części obrad. W czasie pierwszej sesji ogólnej przedstawione zostały 3 wykłady wprowadzające w tematykę spotkania. Jako pierwszy głos zabrał Angelo Di Berardino OSA, który wygłosił wykład inauguracyjny zatytułowany Lex et religio. Una nota introduttiva, a następnie wysłuchano dwóch innych wykładów, które zaprezentowali: Giulia Piccaluga (Roma), Adnuente Deo: riscrivere la legge alla luce dei valori cristiani oraz Paul Mattei (Lyon), Le christianisme comme ,, loi” chez les auteurs latins du milieu du III siècle (Cyprien, Novatien, Commodien). Następnie ogłoszono przerwę obiadowa, po której rozpoczęły się prace w trzech grupach tematycznych.

Pierwsza grupa referatów (sekcja „A”: moderator - prof. Vittorino Grossi OSA) ogniskowała się wokół tematu Zagadnienia biblijne i dyscyplinarne (Temi biblici e disciplinari). W ramach tej grupy swoje przedłożenia przedstawili: Mario Cimosa (Roma) - Gilian Bonney (Rzym), Lex et religio in the Book of Job: according to the Greek text (LXX) and the interpretation of some Christian exegetes; Felix Albrecht (Getynga), Moyses dicit: Philologische Beobachtungen zum Pentateuch der Lex Dei; Igor Filippov (Moskwa), Ius and lex in the Vulgate; Gabriele Marasco (Rzym), La giurisdizione del vescovo e il reato di magia; Antonella Di Mauro Todini (Catanzaro), Divinazione, eresia e magia nella legislazione degli imperatori cristiani; Gaetano Colantuono (Bari), Il coniugium fra religio e lex: i matrimoni interreligiosi nel IV secolo.

Drugą grupę (sekcja „B”: moderator - prof. Francesca Cocchini, stanowiły tematy dotyczące Ojców łacińskich (Padri latini). Referaty wygłosili: Marcin Wysocki (Lublin), Fides in regula posita est, habet legem et salutem de observatione legis (Tertullian, De Praesc. 14). Legal description of the faith by Tertullian - preparing for Constantine's turn and Ecclesiastical Law?; Domenico Ciarlo (Genua), La vera legge in rapporto alla vera religione nell'apologetica di Lattanzio; Ivan Bodrožic (Zagrzeb), Non recipit mendacium veritas, nec patitur religio impietatem. La reazione di sant'Ilario contro la legislazione dell'imperatore Costanzo; Viola Gheller (Trydent), Et tunc primum erubuit Damasus. Damaso, i luciferiani e l'editto Cunctos populos; Maria Rosa Petringa (Katania), Religio e ius romanum nel De errore profanarum religionum di Firmico Materno.

Trzecia grupa referatów (sekcja „C": moderator - prof. Elio Dovere) dotyczyła Tematyki prawa rzymskiego (Temi di diritto romano). Wysłuchano następujących referatów: Teresa Sardella (Katania), Lex, ius, traditio, consuetudo: forme e realtŕ delle fonti autoritative nella documentazione romana tra IV e V secolo; Paola Cuneo 
(Mediolan), Il diritto romano tardo imperiale in materia ecclesiastica nelle fonti letterarie e patristiche; Ilaria Ramelli (Mediolan), La legislazione religiosa di Costantino e i suoi antecedenti; László Odrobina (Szeged), Lex et religio nella legislazione scolastica dei primi imperatori „cristiani”; Giorgio Barone-Adesi (Catanzaro), Lex Dei e lex christiana nella trasmissione orientale della tradizione giuridica romana; Esteban Moreno Resano (Saragossa), La definición legal de los cultos tradicionales en la legislación constantiniana.

Pierwszy dzień zakończył się rautem w ogrodach Instytutu Patrystycznego „Augustinianum", który był okazją do mniej oficjalnych spotkań i rozmów.

Drugi dzień ( $10 \mathrm{~V}$, piątek) obrad badaczy antyku chrześcijańskiego wypełniony był pracami w grupach tematycznych. Pierwszą grupę (sekcja „A": moderator - prof. Carlo Dell'Osso) stanowili ponownie badacze Ojców tacińskich (Padri latini), którzy wysłuchali referatów Camille Gerzaguet (Lyon), Nescit Ecclesia publicas leges... Chiesa e legge nel „De fuga saeculi” di Ambrogio di Milano; Emanuele Di Santo (Messina), Il concetto di lex christiana nell'apologetica romana di fine IV secolo: l'Ambrosiaster e le Consultationes Zacchaei et Apollonii; Paul Rigby (Ottawa), The significance of Cicero's teaching on civil law and eternal law for Augustine's treatment of Donatists and Catholics; Carlos Buenacasa Pérez (Barcelona) - Raúl Villegas Marín (Paryż), Agustín, autor intelectual del texto del edicto de unión de 405; Geoffrey Dunn (Brisbane), Zosimus and the Pardon of Caelestius; Bronwen Neil (Brisbane), The Decretals of Gelasius I: making Canon Law in Late Antiquity.

Druga grupa (sekcja „B”: moderator - prof. Emanuela Prinzivalli) zajmowała się Ojcami greckimi (Padri greci) i wysłuchała następujących przedłożeń: Jeffrey Bingham (Dallas), Lex and religio in Irenaeus of Lyon; Gabriella Aragione (Strasbourg), Forza del tempo, autorità delle leggi ed evoluzione dell'umanitŕ secondo Origene; Juana Torres Prieto (Santander), De epistolas privadas a cánones disciplinarios: las „cartas canónicas” de Basilio de Cesarea; Edinei da Rosa Cândido (Florianópolis), Matrimonio e legge nel Discorso 37 di Gregorio Nazianzeno; Roberto Osculati (Katania), Gerarchia delle leggi nelle „Omelie sulla lettera ai Romani” di Giovanni Crisostomo; Mariangela Monaca (Messina), La forza della vera religio e le „leggi dei pescatori". Annotazioni da ,La cura delle malattie elleniche” di Teodoreto di Cirro; Kevin Wagner (Melbourne), The Authority and Power of a Regional Bishop in Late Antiquity. A Case Study based on the Letters of Synesius of Cyrene.

Trzecia grupa referatów (sekcja „C”: moderator - prof. Alberto Camplani), w sesji przedpołudniowej, podejmowała temat: Armenia $i$ Egipt (Armenia ed Egypto). Swoje badania zaprezentowało trzech badaczy: Francesco Aleo (Katania), Legge naturale e legge divina in un Logos dello Ps.-Macario Egizio (Log. I, Coll. III); Alessandro Orengo (Piza), Legge e religione nell'Armenia del IV e V secolo; Marco Bais (Rzym), Legge e religione negli autori armeni più antichi (secc. IV-VIII).

$\mathrm{W}$ sesji popołudniowej dyskusję prowadzono również w trzech grupach tematycznych, z których pierwsza (sekcja „A”: moderator - prof. Paolo Siniscalco) podjęła temat: Kościót i Imperium (Chiesa e Impero), prelegentami zaś byli: Vittorino Grossi OSA (Rzym), La nozione di „, Chiesa cattolica” tra religione cristiana e legge romana; Jean-Marie André (Paryż), Lex e religio nei primi dibattiti della „reazione pagana"; María Victoria Escribano Pańo (Saragossa), Religio et lex: episcopal legationes and imperial leges in Late Roman Africa (CTh 16. 2. 31/ CTh 16. 5. 46/ Sirm 14 [409]); Marianne Sághy, Imperial Legislation and Papal Jurisdiction in Context: 
the Rescript of 378; Rossana Barcellona (Katania), Le trame giuridiche della societr' nella prospettiva conciliare (Gallia secc. V-VI).

W drugiej grupie tematycznej (sekcja „B”: moderator - prof. Angelo Di Berardino OSA) zajęto się tematem: Teodozjusz - Justynian (Teodosio - Giustiniano), swoje zaś referaty przedstawili: Alessandro Saggioro (Rzym), Nomen Christianum e nomina monstruosa: paradigmi dell'identità nel ,C Codice Teodosiano”; Josef Rist (Bochum), Das Edikt „Cunctos populos” des Theodosius und der Aufstieg des Christentums zur Staatsreligion; Andrea Cococcia (Roma), His, qui ex christianis pagani facti sunt; Spyros P. Panagopoulos (Kalamata), Religion et ius publicum sous Théodose et Justinien; Juan Antonio Bueno Delgado (Alcalá de Henares), Lex et religio en las Novelas de Justiniano I; Gianluca Pilara (Rzym), Clerici apud proprios episcopos primum conveniantur. Una nota in merito ai tribunali ecclesiastici nel diritto giustinianeo.

Trzecia zaś grupa referatów (sekcja „C": moderator - prof. Giuseppe Caruso OSA) obejmowała różną tematykę (Temi vari), a prelegentami byli: Josep Vilella Masana (Barcelona), Los catecúmenos en los preceptos pseudoiliberritanos; Mar Marcos (Santander), Anti-Pelagian Legislation in Context; Jérémy Delmulle (Paryż), Non solum apostolicis, sed etiam regiis edictis (Prosper, C. coll., 21, 1). L'action de Boniface contre les pélagiens, un modèle pour Sixte III?; Margarita Vallejo Girvés (Alcalá), Decreto de destierro sin juicios previos. El caso del patriarca Macedonio II de Constantinopla según Teófanes Confesor, Chron. a. m. 6004, ad a. 511-512; Arduino Maiuri (Rzym), „Da iudex vice Caesaris a iudex vice Christi”. Immagini antiche ed equilibri moderni nel tardoantico.

$\mathrm{W}$ ostatnim dniu obrad (12 V, sobota) najpierw wysłuchano referatów w dwóch grupach tematycznych. W pierwszej (sekcja „A”: moderator - prof. Rocco Ronzani OSA) omawiano zagadnienia związane z Grzegorzem Wielkim (Gregorio Magno), a referaty zaprezentowali: Lisania Giordano (Katania), Religio delle genti in Gregorio Magno; Mario Iadanza (Neapol), La vendita dei vasi sacri per il riscatto dei prigionieri nell'epistolario di Gregorio Magno; Clara Polacchi (Rzym), La manumissio dei mancipia nelle lettere di Gregorio Magno, tra norma giuridica e istanza religioso-caritativa.

W grupie drugiej (sekcja „B”: moderator - prof. Massimiliano Ghilardi) zajęto się Epigrafia i ikonografia (Aspetti epigrafici e iconografici); wysłuchano zaś następujących referatów: Esther Sánchez Medina (Alcalá de Henares), Epigrafia, Religio et Lex: el hábito epigráfico cristiano en la península ibérica durante la antigüedad tardia; Gabriele Pelizzari (Mediolan), Dominus Legem dat. Le origini cristiane tra Legge e leggi: la documentazione iconografica.

Ostatnim punktem obrad XL Dni Augustiańskich była sesja plenarna prowadzona przez prof. Antonio Nazzaro Ramón, w czasie której swoje wykłady przedstawili: Ramón Teja Casuso (Santander), Ius humanitatis, ius aequitatis, ius fraternitatis como fundamentos de un derecho universal en las Instituciones de Lactancio oraz Elio Dovere (Neapol), Lex catholica e ius principale a Roma: gli anni della prima codificazione ufficiale. Na zakończenie obrad głos zabrał ponownie dyrektor Instytutu Patrystycznego „Augustinianum” - o. prof. Robert Dodaro, który podziękował prelegentom za wygłoszone referaty, słuchaczom za obecność oraz zaprosił na XLI Dni Augustiańskie w roku 2013, których tematem będzie: Teologia od V do VIII wieku: rozwój i kryzys. 
W ten sposób do historii przeszło jubileuszowe 40. spotkanie patrologów pod gościnnym, odremontowanym dachem Instytutu Patrystycznego „Augustinianum”. Szkoda tylko, że tak mała ilość Polaków prezentuje swe badania patrystyczne na tym jednym z najważniejszych spotkań badaczy antyku chrześcijańskiego. Piszący te słowa był jedynym mówcą podczas spotkania, wśród słuchaczy można zaś było dostrzec trzch innych Polaków. Pozostaje nadzieja, że kolejne dni patrystyczne w „Augustinianum" naznaczone będą większą obecnością polskich patrologów, słuchając bowiem niektórych wystapień, uczciwie można stwierdzić, że mamy czym pochwalić się w zakresie badań nad antykiem chrześcijańskim.

ks. Marcin Wysocki - Lublin, KUL

\section{MUZYKA W BIZANCJUM: KANON PASCHALNY JANA DAMASCEŃSKIEGO \\ (Sympozjum bizantynistyczno-patrystyczne połączone z koncertem muzyki bizantyńskiej, Lublin, 17 V 2012)}

Dnia 17 V 2012 (czwartek) w KUL-owskim Kolegium Jana Pawła II (sala nr 1031) odbyło się sympozjum bizantynistyczno-patrystyczne, którego organizatorami była Katedra Historii Bizancjum KUL (Wydział Nauk Humanistycznych), kierowana przez piszącego te słowa, i Katedra Historii Kościoła w Starożytności Chrześcijańskiej KUL (Wydział Teologii), której kierewnikiem jest ks. dr hab. Piotr Szczur, prof. KUL. Temat rzeczonego sympozjum brzmiał: Muzyka w Bizancjum: „Kanon paschalny" Jana Damasceńskiego. Spotkanie to zostało pomyślane jako swego rodzaju słowo wstępne, poprzedzające wykonanie Kanonu paschalnego Damasceńczyka. Kanon ten został zaśpiewany w języku greckim przez wspomniany wyżej Męski Chór Kameralny im. Bogdana Onisimowicza pod dyrekcją Marcina Abijskiego.

Prelekcje rozpoczęły się o godzinie 13.30. Pierwszym referentem był powszechnie znany i ceniony badacz antyku chrześcijańskiego ks. prof. dr hab. Stanisław Longosz (Lublin, KUL). Temat jego wystąpienia brzmiał: Muzyka w pismach Ojców Kościoła. Mówca wprowadził słuchaczy w szeroko rozumiane zagadnienie muzyki i śpiewu sakralnego w pismach patrystycznych, a także podniósł problem stosunku muzyki wczesnochrześcijańskiej do muzyki grecko-rzymskiej i żydowskiej. Następny prelegent, którym był kierownik Katedry Teologii Prawosławnej w Instytucie Ekumenicznym (Wydział Teologii KUL), dr hab. Krzysztof Leśniewski, prof. KUL, omówił teologiczne aspekty kanonu Jana z Damaszku (ok. 675-749). Jego referat nosił tytuł „Kanon paschalny” św. Jana Damasceńskego jako liturgiczne urzeczywistnienie duchowości hezychastycznej. Trzecie wystapienie, którego tematem była Struktura bizantyńskiej formy kanonu i liturgiczne implikacje muzyczne między Wschodem a Zachodem, wygłosił pracownik Katedry Monodii Liturgicznej w Instytucie Muzykologii (Wydział Teologii KUL), ks. dr Piotr Paćkowski. Autor wystapienia podkreślił głębię muzyki bizantyńskiej, która jest często trudna zarówno do uchwycenia, jak i do zrozumienia przez słuchaczy wychowanych w zachodnim kręgu kulturowym. Wreszcie ostatni, czwarty referat, którego autorem był Marcin Abijski, dyrygent Męskiego Chóru Kameralny im. Bogdana Onisimowicza i doktorant w Katedrze Teologii Prawosławnej, nosił tytuł Bizantyński śpiew liturgiczny. Prelegent podkreślił znaczenie 